\title{
O gênero do cuidado de si: as implicações da dieta alimentar na comensalidade de diabéticos*
}

\author{
Andréia Aparecida Ferreira Lopes ${ }^{* *}$
}

\begin{abstract}
Resumo
A partir da pesquisa de campo em uma associação de diabéticos na cidade de São Paulo, Brasil, o artigo problematiza o fato de que nas situações de comensalidade no âmbito familiar, o cuidado de si representa um desafio para as práticas sociais do grupo pesquisado - homens e mulheres entre 53 e 90 anos. A prática do cuidado de si confronta as representações de gênero em torno do papel feminino de cuidadora, apontando para a quebra do circuito de troca familiar nos momentos de comensalidade.
\end{abstract}

Palavras-chave: Comensalidade, Cuidado de Si, Diabetes, Gênero, Relações Familiares.

\footnotetext{
* Recebido para publicação em agosto de 2009, aceito em março de 2011. Uma versão anterior deste artigo foi apresentada no IX Coloquio de la RED Antropología Médica "Alimentación, Salud y Cultura", Tarragona, Espanha, 4 a 5 de junho de 2009.

** Grupo de Pesquisa Gênero e Envelhecimento, UNICAMP. andreia-f@uol.com.br
}

cadernos pagu (36), janeiro-junho de 2011:345-374. 
O gênero do cuidado de si

The gender of self-care:

the implications of the diet in the diabetics' commensalism

\begin{abstract}
The article questions the way by which the family commensal situations represent a challenge to the diabetics who are engaged with the practices of taking care of themselves. From the field research in an association of diabetics in the city of São Paulo, Brazil, the analysis shows how the researched group - men and women between 53 and 90 years - deals with the changes in their social practices while they try to take care of the diabetes. The practice of taking care of the self confronts the gender representations around the caretaker's feminine role, and points to the break of the family relationship of exchange.
\end{abstract}

Key Words: Commensalism, Care of the Self, Diabetes, Gender, Familiar Relationships. 
Andréia Aparecida Ferreira Lopes

\section{Introdução}

Uma das questões centrais nos cuidados que os diabéticos têm que ter com sua saúde diz respeito à dieta. As suas práticas alimentares podem se tornar carregadas de novos sentidos relacionados à familiarização com o universo de saberes da nutrição. Orientados pelo conceito de alimentação adequada para diabéticos, suas práticas alimentares passam a incluir ponderações acerca da quantidade e qualidade nutricional dos alimentos, da frequência das refeições, além de critérios de avaliação e escolha dos alimentos - como o caso do estímulo à prática de verificação dos ingredientes nos rótulos dos alimentos.

Um dos temas que chama atenção na pesquisa junto a diabéticos ${ }^{1}$ é o impacto que a reorientação da dieta tem sobre algumas práticas alimentares caracterizadas pela comensalidade entre amigos e parentes - as visitas, os almoços de domingo junto com a família e outros encontros festivos. Essas situações são associadas a um conjunto de constrangimentos relativos às restrições alimentares que o cuidado com a diabetes requer. Mesmo que as "trapaças" na dieta - que a literatura reconhece como uma prática relativamente frequente entre diabéticos, $e$ muitas vezes admitidas no grupo pesquisado - eventualmente deixem passar despercebida a diabetes, a dimensão de conflito ou de inquietação por vezes persiste no mal-estar que as situações de comensalidade representam para alguns diabéticos.

O conflito ou a inquietação presentes nessas situações apontam para o impacto que a prática do cuidado de si tem

1 A pesquisa "Assumindo o cuidado de si: identidade e práticas associativas entre diabéticos" (Programa de Pós-Graduação em Antropologia SocialIFCH/UNICAMP) foi orientada por Guita Grin Debert e contou com o apoio da Fundação de Amparo à Pesquisa do Estado de São Paulo-FAPESP. A tese de doutorado analisa o modo como a experiência da diabetes orienta os indivíduos nas práticas de cuidados com o corpo, de redefinição de estilos de vida e de participação associativa, temas que caracterizam as relações entre formas de sociabilidade e de corporalidade contemporâneas. 
O gênero do cuidado de si

sobre as relações sociais da pessoa diabética. A referência recorrente sobre o mal-estar no compartilhamento da refeição suscitou o questionamento acerca de qual seria a natureza das representações que lhe dão expressão. O que estaria em jogo nas narrativas acerca das dificuldades de se compartilhar as refeições com os familiares? De que forma essa questão pode iluminar a reflexão acerca da reestruturação da identidade das pessoas diabéticas e de suas relações sociais, e das práticas de comensalidade de uma maneira mais geral?

Como lembra Denise Sant'Anna (2003), a alimentação tem se tornado um tema privilegiado para o conhecimento do próprio corpo, e, tal como sexo, em muitos casos é considerada "uma experiência que envolve grandes liberdades e prazeres, mas, também, muitas coações, proibições e tabus" (id.ib.:42). Segundo a autora, dois movimentos simultâneos acompanham a ampliação das preocupações em torno do ato de comer: os ideais hoje bem aceitos de beleza, saúde, higiene e elegância; e a intensificação das preocupações com a saúde e com investimentos médicos e industriais que tomam o corpo como assunto prioritário e urgente (id.ib.:42-3).

O tema da alimentação também tem chamado a atenção da antropologia para as transformações que a prática da comensalidade tem sofrido nos contextos urbanos. Como é colocado por Mabel Gracia Arnaiz (2005), o comensal estaria se convertendo em um indivíduo mais autônomo em suas escolhas, sendo que a ampliação do "espaço de tomada de decisão alimentar" estaria conduzindo ao

desenvolvimento das porções individuais ou a multiplicação dos cardápios específicos para diferentes comensais da mesma mesa, como no caso das comidas familiares, em que os meninos, o marido e a esposa comem pratos diferentes (id.ib.:155). 
A autora lembra que apesar do fato de as práticas de refeições em família estarem se reduzindo, assim como o tempo de sua preparação e compartilhamento, é possível verificar casos de aumento das comidas de caráter social, tanto públicas quanto privadas. $^{2}$

Os problemas que os diabéticos têm com as ocasióes de comensalidade certamente se constituem como um objeto de análise estratégico capaz de permitir o acesso a aspectos importantes das relações familiares. Depois de afirmar que a nutrição é um processo biológico mais fundamental que o sexo, Audrey Richards (2004) enfatiza a sua relevância para a vida social:

Na vida do organismo individual ela é a primeira e mais recorrente necessidade física, enquanto que na espera mais geral da sociedade humana ela determina, mais amplamente que qualquer outra função fisiológica, a natureza dos grupos sociais e a forma que tomam suas atividades (id.ib: 1$)^{3}$

Por um lado, esse questionamento se liga à afirmação de Rosa Garcia (2005), quando analisa a aplicação da antropologia às áreas da nutrição:

Nas práticas alimentares estão contidas a identidade cultural, a condição social, a memória familiar expressa nos

\footnotetext{
2 A autora aponta múltiplas possibilidades de comer em grupo, dando espaço à "função comensal e recriação da identidade coletiva: tradições populares, reuniões de amigos, celebrações familiares, comensalidade do trabalho, festas escolares, atos empresariais e institucionais, comemorações histórico civis, atividades esportivas e de ócio, ritos de passagem etc" (ARNAIZ, 2005:159).

3 "In the life of the individual organism it is the more primary and recurrent physical want, while in the wider sphere of human society it determines, more largely than any other physiological function, the nature of social groupings, and the form their activities take" (RICHARDS, 2004:1).
} 
O gênero do cuidado de si

procedimentos relacionados à escolha e à preparação do alimento e ao seu consumo propriamente dito... (id.ib.:277).

Nesse sentido, pergunto-me de que modo os constrangimentos sentidos nas situações de comensalidade se relacionam à própria identidade da pessoa enquanto diabética. De que forma essa identidade se confrontaria com a sua história familiar e com a manutenção das relações desse contexto?

Os estudos antropológicos sobre alimentação mostram que a comensalidade tem um papel central para a reprodução dos laços e das relações afetivas nos diferentes grupos sociais. Nela, a comida mais farta e os pratos preferidos alimentam "simultaneamente os laços e as relações afetivas", e o compartilhamento das sensações produzidas pela refeição coletiva concorre para a atualização da coesão grupal. ${ }^{4}$

Por outro lado, este trabalho se concentra no modo como o constrangimento pela recusa ao oferecimento, ou pela prática de limitação, dos alimentos na situação de comensal remete à quebra de uma relação de troca. Nesse sentido, reporto-me ao complexo da dádiva nos termos em que Marilyn Strathern (2006) se refere, mais especificamente, à troca não-mediada; e também no sentido que tem iluminado, por exemplo, a análise das práticas de hospitalidade que cercam a comida no Brasil. ${ }^{5}$

\section{Cuidar da diabetes}

Este trabalho se baseia nos achados da pesquisa desenvolvida em uma associação de diabéticos na cidade de São Paulo, Brasil. O trabalho de campo inclui a observação das atividades semanais que congregam grupos de diabéticos, com um número de participantes que varia de 12 a 18 pessoas, e que acontecem na sede da associação. Essas atividades são dirigidas

${ }^{4}$ Cf. Maciel, 1996.

5 Cf. DaMatta, 1986. 
aos associados com o objetivo de informá-los e orientá-los sobre como lidar com a diabetes. As orientações implicam tanto a familiarização com ideias e conceitos da biomedicina acerca da compreensão dos processos fisiológicos relacionados à enfermidade, como a introdução em um universo amplo de conhecimento acerca de hábitos e práticas de cuidado de si, os quais vão desde as técnicas para a realização de hemoglicotestes ${ }^{6}$ e de aplicação de insulina, passando por considerações acerca da prática de atividades físicas, chegando nos conceitos sobre alimentação saudável.

Além das atividades de caráter mais educativo, a associação mantém dois grupos de psicoterapia, os quais também se reúnem semanalmente. Além da observação dessas atividades, a pesquisa também envolveu entrevistas semi-estruturadas com 12 associados selecionados.

Os associados que frequentam semanalmente a associação são velhos ${ }^{7}$, com idades que vão dos 53 aos 90 anos. A grande

\footnotetext{
6 Hemoglicoteste é a prática de tomar a medida de glicemia sanguínea com o auxílio do glicosímetro. Também é chamada de "destro", termo que é usualmente encontrado nas mensagens postadas nas comunidades virtuais de diabéticos do Orkut, e que alguns dos associados que entrevistei identificam como sendo o termo geralmente usado nos hospitais. No discurso educativo da associação, a prática de medir a glicemia é referida como sendo a de "fazer monitorização", quer dizer, monitorar a glicemia durante o dia, medindo-a idealmente antes e após as refeições. Com esse fim, a pessoa opera o glicosímetro, aparelho que aponta o índice de glicemia a partir de uma amostra de sangue extraída de um dos dedos da mão. Na prática os diabéticos que mais se dedicam a realizar esses hemoglicotestes são os que apresentam uma variação glicêmica maior durante o dia, implicando a necessidade de um controle mais estrito, a fim de evitar hipoglicemias ou hiperglicemias severas. Contrariando essa orientação, tenho verificado vários casos em que os associados fazem o hemoglicoteste apenas uma vez ao dia, ou quando sentem algum mal-estar, ou, ainda, somente quando vão à associação.

7 O uso do termo velho se refere à elaboração simbólica com a qual o processo biológico dos indivíduos é investido. Trata-se, portanto, de uma categoria de idade tal como definida pelo processo de institucionalização do curso da vida, próprio da modernidade. Cf. Debert, 2004:39 e 50-69.
} 
O gênero do cuidado de si

maioria das pessoas é composta por mulheres - das 12 pessoas que entrevistei, 8 são mulheres. Embora alguns membros apresentem algumas características que os definem como fazendo parte de camadas médias - ter curso superior, a condição de profissional liberal ou terem desenvolvido atividades como pequenos comerciantes, como é o caso de 3 dos entrevistados homens e de uma das mulheres -, a grande maioria faz parte das camadas populares. São aposentados. Entre as mulheres, $50 \%$ moram só - nesse caso, são viúvas -, duas delas moram com o marido, sendo que a unidade familiar ainda abriga algum filho solteiro; das outras duas mulheres, uma é separada e mora com dois filhos solteiros e a outra mora com a família da filha. Geralmente, a presença masculina nos grupos organizados pela associação não ultrapassa os $25 \%$. Dos quatro homens entrevistados, dois ainda mantêm a unidade familiar constituída por esposa e filhos, o terceiro mora com a esposa, tendo os filhos já casados, e o quarto é solteiro e mora só.

Com exceção de dois homens cuja diabetes é do tipo 1 , adquirida na juventude (quando o primeiro deles tinha 18 anos, e o segundo 24), todos os demais entrevistados são diabéticos do tipo 2, doença que se manifesta tardiamente na vida da pessoa, geralmente após a idade de 40 anos. Essa é a situação de 10 entrevistados. Para estes, de modo geral, a diabetes foi diagnosticada através de exames de glicemia, quando em consultas médicas apresentaram queixas sobre mal-estares geralmente relacionados à situação de taxas elevadas de açúcar no sangue, como: urina em excesso, boca seca, visão turva, fome excessiva, dores nas pernas, entre outros. Tornar-se diabético se conjugou, assim, à fase de vida mais madura, caracterizada pelo envelhecimento do ciclo de vida doméstico, tendo-se os filhos já adultos, frequentemente casados e tendo constituído unidades domésticas próprias. Desse modo, a diabetes encontrou, por assim dizer, a maioria dos entrevistados relativamente desvinculados ou menos comprometidos com as obrigações do trabalho - são pessoas aposentadas - ou de apoio e suporte familiar e, por isso, 
com mais condições de se dedicarem às práticas de cuidado com sua saúde. Nesse contexto, conta muito a própria disponibilidade de participar das atividades da associação, que ocorrem, sobretudo no período da tarde, e nos dias úteis. Ademais, incluir os hábitos saudáveis na vida cotidiana pode implicar, por exemplo, em se dedicar a uma atividade física como a hidroginástica ou a caminhada; alterar o horário das refeições e incluir horários para ingestão de medicamentos e para medir a glicemia; alterar a forma de preparação dos alimentos, os cardápios e suas quantidades. As considerações que faço mais adiante podem dar uma ideia mais clara acerca do impacto dessas práticas na vida do diabético, mais especificamente no caso do compartilhamento das refeições que são centrais na dinâmica familiar.

É bastante variável o grau em que os diabéticos da associação se engajam realmente na mudança dos hábitos alimentares, a partir da orientação e do incentivo produzidos nas atividades das quais participam.

De modo geral se pode dizer que, entre os associados, o diabético digno de respeito, enquanto aquele que sabe se cuidar, de forma alguma se traduz pela pessoa insensível ao prazer dos pratos e da forma de alimentação tidos como inadequados à dieta saudável. Claro que existem aqueles que se mostram mais preocupados em seguir rigorosamente as recomendações médicas: "Eu me condicionei a não comer nada com açúcar", como se expressou certa vez uma associada; "faço tudo direitinho", como outra descreveu suas práticas de autocuidado. Todavia, de modo geral faz parte dos atributos do bom diabético a habilidade de saber entregar-se à sedução dos pratos mais desejados, compensando os "abusos" com um controle maior na dieta do dia seguinte, por exemplo. ${ }^{8}$ Falar sobre os gostos, aliás, se constitui

8 Fundamentalmente, a essa figura se contrapõe o que os associados denominam de diabético "revoltado", que ainda "não aceitou a diabetes", e que se comporta como se não fosse diabético, demonstrando ser totalmente descuidado para consigo, e no que diz respeito à dieta em particular. 
O gênero do cuidado de si

por uma prática muito comum nas frequentes rodinhas de conversas animadas que caracterizam o ambiente da associação. Nelas um dos maiores divertimentos se relaciona às confidências sobre os desejos que se nutre em comer pratos doces, ou aqueles tidos como calóricos ou gordurosos a partir das classificações do saber da nutrição.

Acompanhando as conversas mais animadas dos grupinhos de diabéticos da associação é possível perceber o quanto o tema das "comidas gostosas" resiste a despeito de todo processo educativo que procura ressaltar o caráter nutricional dos alimentos. Nas manifestações de identificação que essas conversas proporcionam é marcante a expressão do prazer que alguns alimentos despertam de forma especial, por exemplo: a pizza, o pastel da feira, a feijoada, o bolo confeitado e os docinhos das festas, o chocolate, e assim por diante. Ao mesmo tempo em que se toma consciência das práticas saudáveis de limitar a quantidade dos alimentos para evitar que a glicemia se eleve demasiadamente, muitos diabéticos comemoram uma hipoglicemia, já que a situação os "franquia" uma refeição mais caprichada e "sem culpa". "É isso que mata o diabético: diabético não pode comer isso, não pode comer aquilo...", como desabafou uma associada em uma aula de nutrição.

Na verdade, muitas vezes a prática do controle da glicemia através dos hemoglicotestes acaba orientando o diabético quanto à possibilidade de cometer alguns "abusos" na comida. Quando a glicemia está baixa, a noção é de que há uma margem que pode ser usada para se comer um pouco a mais, por exemplo. Esse é o tipo de controle característico da pessoa que tem diabetes do tipo 2 , e que não faz uso de insulina. No caso dos diabéticos do tipo 1 , entretanto, o uso de insulina permite um relaxamento bem maior quanto à dieta. Essa é a perspectiva da "contagem de carboidratos", técnica que orienta o diabético a "corrigir" sua glicemia de acordo com os alimentos que ingere em uma 
refeição. ${ }^{9} \mathrm{~A}$ insulina ultra-rápida permite como que neutralizar, se é possível dizer assim, o efeito de uma refeição sobre a glicemia sanguínea.

Os dados aqui analisados dizem respeito a alguns relatos sobre as dificuldades encontradas em manter a prática do cuidado de si nas situações de reunião familiar. São duas as preocupações básicas com a prática alimentar evocadas pelos relatos. A primeira preocupação diz respeito à evitação de determinados alimentos inadequados à manutenção do controle glicêmico - aqueles que fazem a glicemia subir e que são principalmente os que contêm açúcar, mas também são incluídos os alimentos considerados muito gordurosos ou ricos em carboidratos. A segunda preocupação diz respeito ao horário das refeições. A orientação dada aos diabéticos é a de cuidarem para aumentar o número de refeições diárias, mantendo certo rigor no intervalo de três horas entre as mesmas. Com essa disposição, a quantidade de alimento deve ser menor em cada refeição. Essa estratégia se explica pelo objetivo de manter o nível de glicemia sanguíneo o mais constante possível, evitando-se picos de alta - hiperglicemia, a hiper, como é chamada pelos diabéticos - e de baixa glicemia - hipoglicemia, a hipo.

\section{Cuidar de si X Cuidar do outro}

Ao tratar da distinção entre comida e alimento, Roberto DaMatta (1986) afirma que

\footnotetext{
9 A técnica da contagem de carboidratos está associada ao uso da bomba de insulina, dispositivo que permanece ligado ao corpo da pessoa através de uma agulha de polietileno. A pessoa fica livre da prática convencional de injeção de insulina através de seringas ou canetas de aplicação. $\mathrm{O}$ número de picadas diminui, uma vez que o local da agulha que conecta a bomba ao corpo da pessoa deve ser trocado a cada dois ou três dias. A prática de injeção de insulina fica resumida a operar o dispositivo que libera a quantidade de insulina que a refeição requer depois de feito o cálculo da quantidade de carboidratos ingeridos.
} 
O gênero do cuidado de si

Comida não é apenas uma substância alimentar, mas é também um modo, um estilo e um jeito de alimentar-se. $\mathrm{E}$ o jeito de comer define não só aquilo que é ingerido como também aquele que ingere (id.ib.:56).

Como coloca Maria Eunice Maciel (2001), as "cozinhas" ou "sistemas alimentares" são

práticas alimentares diversificadas que compreendem um conjunto de alimentos que relacionam-se às representações coletivas, ao imaginário social, às crenças do grupo enfim, a suas práticas culturais (id.ib.:150).

Fazem parte de seu estudo questões como: o quê, como, quando e com quem se come. A cozinha, assim, se constitui como uma prática através da qual se produzem, e se reproduzem, identidades. Esse é o caso, por exemplo, da forma como a mulher dona-de-casa da classe trabalhadora é definida por seu desempenho na cozinha. Ana Maria Canesqui descreve os atributos morais sobre a boa dona-de-casa prevalecente na comunidade que pesquisou:

Saber cozinhar, preparar a comida para o marido e os filhos e não para si, cuidar caprichosamente da comida, 'não descontrolar o fogão', o que implica evitar qualquer desperdício, e 'ser trabalhadeira', a que se move constantemente no espaço da casa... (CANESQUI, 2005:187-8).

Mais recentemente Viviane Assunção (2008) se refere a dois aspectos da experiência de mulheres das classes médias e populares na cozinha, em um município de Santa Catarina, Brasil. Por um lado, como donas-de-casa, cozinhar significa cozinhar para alguém, uma atividade realizada para os outros membros da família (id.ib.:6). Por outro lado, o saber culinário que a mãe detém, tanto acerca da melhor forma de preparo da comida como acerca dos gostos dos filhos, caracteriza uma relação de poder 
que se torna evidente através do sistema de transmissão de saber culinário mediado pelo segredo - entre mães e filhas, irmãs, cunhadas e entre sogras e noras (id.ib.:8 e 10-11).

Contrastando com a tendência para o cuidado com o outro, que caracteriza o papel da mãe e esposa na cozinha, o cuidado de si na prática alimentar das mulheres diabéticas foi tomando uma dimensão analítica ao longo da pesquisa.

Outros pesquisadores dos diabéticos já apontaram as inflexões que o gênero provoca nas práticas de autocuidado:

Em sua pesquisa em bairros pobres em Avellaneda, Província de Buenos Aires, Argentina, Patricia Pittman (1999) nota que para as mulheres o papel de cuidadora é central no modo como explicam tanto o aparecimento da diabetes como a razão pela qual elas próprias não se tratam adequadamente. Não poder suprir as necessidades dos filhos lhes causam nervios (id.ib.:9), e a diabetes é entendida como consequência dessa situação. Entre os dados da autora, o autocuidado é mencionado como egoísta, contraposto à atitude materna e à disposição de ajudar as pessoas: "Yo creo que ser madre te condiciona. Dejás de ser para vivir por el outro", argumenta uma das entrevistadas da autora (id.ib.:19). Sob condições de carência, as mães tendem a sacrificar suas necessidades próprias optando por comprar o alimento para os filhos.

Entre as entrevistas dos pacientes diabéticos em dois hospitais de Porto Alegre-RS, Brasil, Regina Witt observa uma

... nítida diferença nas respostas obtidas com diabéticos do sexo masculino e do sexo feminino à afirmação: "Eu penso primeiro em mim". Diabéticos do sexo masculino escolhiam sem hesitar a afirmativa sempre, enquanto que os do sexo feminino hesitavam e depois diziam que "primeiro pensavam no marido e nos filhos e depois nelas mesmas" (Witt, 1996:153, destacado no original).

Grande parte dos relatos nos grupos de psicoterapia que observei na associação se reporta às relações familiares, sendo 
O gênero do cuidado de si

que alguns temas se repetem com maior frequência ou são bem acolhidos pelos participantes que, em geral, demonstram compreender os sentidos ou a posição de quem fala. A homogeneidade do grupo com relação ao curso da vida aposentados, entre 53 e 90 anos, avós - e também com respeito ao sexo - a maioria é de mulheres -, certamente cumpre um papel importante na reincidência dos temas tratados.

A referência aos filhos se faz presente através (1) das preocupações com sua realização profissional e com seus malestares; através (2) das relações de obrigação mantidas com eles como, no caso mais frequente, o cuidado com os netos; (3) dos conflitos nas relações pessoais - quando os pontos de vista são divergentes ou quando são apontados como "pais/mães ausentes", o que engendra sentimentos de fracasso -; e também através (4) das situações de convívio que a manutenção das relações de parentesco enseja - as visitas, reuniões festivas ou temporadas de convívio no período de férias. A ideia de que os filhos representariam a "fraqueza" da pessoa - a despeito de sua condição independente, e de não estar mais morando na mesma casa - foi expressa de forma contundente nos relatos de uma das reuniões do grupo, produzindo o reconhecimento geral dos membros. Pude constatar o quanto essa ideia se harmonizava com outros relatos que costumava presenciar no grupo - os filhos eram objeto de grande preocupação por parte dos associados, as situações de sofrimento ou as dificuldades dos filhos causavam grande sofrimento e infelicidade dos pais. Essa condição marca profundamente a identidade dos participantes dos grupos, através dos quais se estrutura a prática associativa entre diabéticos.

Cuidar dos netos é uma atribuição importante na relação que muitas associadas mantêm com seus filhos e filhas. Essa atividade é uma das que frequentemente causam a ausência às reuniões na associação. Algumas vezes, essa ausência é prolongada, como quando implica ajudar a filha que mora longe com seu recém-nascido, ou quando a filha ou a nora trabalha fora. 
O vínculo familiar e o teor dos laços de apoio aos quais as mulheres do grupo se encontram envolvidas mostram como, através da maternidade, o cuidado com o outro é uma condição que marca profundamente suas experiências, seus saberes e suas sensibilidades.

\section{A diabetes e o cuidado de si - os incômodos nas reunióes familiares}

Elisa contou que geralmente quando visita sua irmã mais nova não há meios de ter controle sobre o horário de comer, pois "Eles vão fazer o almoço lá pras 4 horas da tarde!", e não adiantava ela tentar ajeitar algo para comer, pois tudo sempre estava por ser feito - "nunca tem nada pronto". Apresentou a situação como de grande dificuldade para ela (caderno de campo).

O relato de Elisa se refere a uma condição desconfortável no encontro familiar: ninguém cuida dela. Ela também não sente autonomia para instaurar plenamente suas práticas de autocuidado nesses momentos em que "retorna" à família.

$\mathrm{Na}$ mesma discussão, Ester exemplificou com sua própria experiência o caráter verdadeiro da ideia de que somente a mãe é capaz de cuidar do outro, e que por isso não se poderia esperar que a família assumisse o cuidado com o parente diabético. ${ }^{10}$

O momento do compartilhamento da companhia em família se mostra incompatível com a prática alimentar que a diabetes requer. Isso fica evidente em um exemplo com que Elisa demonstra ao grupo a forma como contornou o problema da alimentação em um passeio à praia, nas férias que passara com a família de um dos filhos:

${ }^{10}$ Contou que seu filho por muito tempo sofrera com um mal que o obrigava a comer a cada 3 horas, e somente legumes cozidos. Chamou a atenção para o enorme cuidado que tinha, deixando as porções já preparadas de antemão. Concluiu dizendo: "Eu fazia porque era mãe, ninguém mais faria isso" (Caderno de campo). 
O gênero do cuidado de si

Elisa contou que também passava longos períodos na praia em companhia dos parentes, mas que sua vantagem era que a casa ficava muito próxima da praia, de modo que isso permitia que desse umas escapadas: "Subo, como alguma coisa e volto". Pelo que entendi dos gestos que acompanharam seu comentário, a atitude de subir e voltar logo em seguida expressava especialmente a vantagem de lhe permitir não chamar muito a atenção (caderno de campo).

A imagem de uma atitude canhestra está presente quando a mulher relata as dificuldades de cuidar de si nas situações de reuniões familiares, nas quais a diabetes parece ameaçar o adequado compartilhamento das refeições, e, portanto, o ritual de atualização da coesão grupal. Será que a identidade de cuidadora é ameaçada quando a mulher instaura uma temporalidade e uma espacialidade próprias do ato de cuidar de si no momento da comensalidade? Será que o cuidado de si da mulher ameaça a coesão familiar? Será que a mulher só "pode" cuidar de si quando está só? Qual o gênero do cuidado de si?

$\mathrm{Na}$ mesma sessão do grupo referida acima, Ernesto se dispôs a ajudar dando um exemplo de sua experiência:

Ele sempre almoçava meio dia, "Isso seja onde eu estiver". Contou que certa vez, em uma viagem que fazia com seu sobrinho, estavam na estrada quando constatou o horário de seu almoço. Ernesto disse ao sobrinho que tinha de almoçar e foi inflexível com relação a este ponto. A situação provocou um desentendimento, já que o sobrinho queria adiar o horário do almoço. Desde então seu sobrinho ficou "brigado" com ele. Tendo essa questão em conta, disse que, da mesma forma, era muito difícil combinar horários com seus filhos para o almoço de domingo.

Contou, então, que resolvera o problema ao decidir que quem quisesse almoçar com ele deveria ir à sua casa, e ele próprio se encarregaria de fazer o almoço, "E tem sido assim desde então" (caderno de campo). 
Ao que parece, Ernesto não demonstrou a mesma atitude canhestra para resolver as dificuldades com o cuidado de si, impondo sua necessidade de maneira bastante resoluta. Ele mora com a esposa, tendo os filhos já casados. Diferentemente de outros homens que entrevistei, Ernesto mantinha uma atitude bastante autônoma no cuidado de si: ele próprio preparava sua comida, por exemplo.

Em outros casos de homens diabéticos, entretanto, as famílias reorientam seus hábitos alimentares para viabilizar a dieta do parente diabético. Esse é o caso de Walter. Perguntei-lhe se os parentes ajudavam no cuidado com a diabetes:

Ajudam sim. Minha família é pequena: são três pessoas. Mas os três são meus parceiros. Minha esposa muito mais. Ela faz tudo que existe numa confeitaria, numa padaria, ela faz em casa pra mim... diet... light! (...) ela faz tudo diet.

Assim como Walter, a família de Henrique também segue uma alimentação diet, de modo que não há diferenças de prática alimentar entre seus membros. Nos dois casos, a unidade doméstica ainda se encontra caracterizada pela integridade estrutural - com esposa e filhos.

Entretanto, Walter e Henrique também se referem às situações de incômodo provocadas pelas restrições alimentares nas reuniões com parentes distantes, nas quais a refeição se reveste de um sentido mais intenso no que diz respeito à recomposição do vínculo identitário.

Isso limita muito a gente. Por exemplo, quando eu falei da minha família, eu falei da minha família: os meus filhos, a minha esposa. Mas a família é grande, então, você vai em uma festa de Natal, e normalmente as pessoas sabendo que eu sou diabético, elas fazem uma sobremesa diet, isso já... vamos dizer assim... é até uma atenção especial daquela pessoa, mas que a gente não gostaria que houvesse isso, né? 
O gênero do cuidado de si

A preocupação em manter o padrão de alimentação saudável - os horários e a qualidade dos alimentos - acaba por representar uma grande dificuldade para as pessoas diabéticas nesses encontros, os quais implicam o mergulho em condições de temporalidade e de espacialidade difíceis de controlar. $\mathrm{O}$ forte apelo para a participação "total" na prática coletiva - as quais teriam o sentido de evocar o compartilhamento do prazer, das sensações e da coesão grupal - transparece no aspecto furtivo $e$ discreto que a refeição solitária deve ter no contexto de reunião familiar - "Subo, como alguma coisa e volto", sem dar muito na vista.

Recusar um doce feito com açúcar na casa de um parente distante, recusar uma caipirinha em uma festa com os amigos, pedir para não adoçar o café que fica na garrafa térmica quando se passa alguns dias na casa do irmão, ter horário para comer, tomar insulina, enfim, as práticas de cuidado de si que o diabético deve ou deveria adotar desafiam as temporalidades $e$ espacialidades das reuniões com amigos e familiares. "É como se você estivesse saindo daquele grupo", como se expressou Henrique referindo-se ao incômodo de se sentir diferente ao recusar o alimento oferecido. Como se, para estar junto comemorar, passear com os amigos, visitar os parentes distantes, enfim -, é preciso comer junto, na mesma hora, os mesmos pratos, no mesmo lugar: ser um verdadeiro comensal.

Parece existir uma diferença entre as exigências da masculinidade $e$ feminilidade para obter sucesso na manutenção da dieta. Os pais e maridos recebem o cuidado de suas esposas, $e$ a família o apóia no cuidado de si, sendo que esse apoio pode chegar ao ponto de todos aderirem à mesma dieta do pai. Dessa forma, os homens aparentemente se encontram em vantagem com relação à legitimidade de suas práticas de autocuidado, o que se reflete em melhores condições para adaptar suas necessidades diferenciadas no contexto das relações sociais. Embora também 
não estejam livres de certos desconfortos ${ }^{11}$, é preciso constatar que o apoio de que dispõem na família dá a eles certo suporte nas "negociações" das situações de comensalidade. É preciso notar, porém, que os pais ou maridos não dominam ou não assumem inteiramente o ato de cuidado em $\mathrm{si}$ - ele antes recebe o cuidado, ou é cuidado.

Com relação às mães e esposas, a questão parece mais difícil. É interessante o modo como Witt coloca a questão:

... o controle metabólico do diabético depende do uso de múltiplas doses de insulina, refeições regulares e de um programa balanceado de exercícios, além do monitoramento da glicose sanguínea em casa. Como conciliar este esquema com a jornada de trabalho das mulheres, visto que está condicionada ao horário do marido e ao dos filhos? (WITT, 1996:154).

A experiência das mulheres idosas que moram só mostra que são justamente as reuniões familiares, ou seja, os momentos de reintegração com a família, que representam maiores desafios para o cuidado de si. A sensação de impotência e fracasso em conciliar esses momentos com os cuidados de si demonstra o quanto essa prática se choca com a identidade de que se revestem diante do grupo. Embora dominem as técnicas do cuidado, no contexto familiar elas são impedidas de as voltarem para si mesmas, pois elas só encontram legitimidade quando orientadas para o cuidado do outro. A performance da mãe e dona-de-casa está, em primeiro lugar, diretamente vinculada ao preparo da refeição para a família, não para si mesma.

Nesse ponto penso que a observação de Richards sobre as sociedades indígenas pode incluir também o caso da sociedade

${ }^{11}$ Refiro-me, por exemplo, aos convites feitos de maneira insistente por agentes que muitas vezes se mostram inconformados com a recusa: "É como se você estivesse saindo daquele grupo, porque todo mundo está ali comemorando: 'Toma uma caipirinha!', 'E você, não toma?', 'Não'. Quer dizer, é muito difícil, né?" (Entrevista com Henrique). 
O gênero do cuidado de si

moderna que analiso aqui: as obrigações de parentesco tendem a ser expressas pela doação e troca de comida (Richards, 2004:210). Comentando sobre o fato de que as maneiras de comer representam as regras da distribuição da comida entre os membros do grupo, Richards afirma que os padrões de comportamento entre diferentes indivíduos nas refeições são expressões de seus respectivos atributos sociais, aprendidos desde a infância. Através deles a criança passa a distinguir sua posição com relação aos demais membros da família, através das distinções de status existentes (id.ib.:67). Para a autora, cada distinção de status pode ser expressa por variações da etiqueta que envolve a prática da alimentação (id.ib.:68).

Como observa a mesma autora, as práticas de preparo, consumo e compartilhamento da comida se associam a profundos sentimentos vividos no seio familiar. Essas práticas simbolizam as atitudes emocionais relativas aos laços familiares (id.ib.:173). É dessa forma, portanto, que fazem parte dos momentos de comensalidade, a expressão do prazer que os alimentos despertam, o qual, sob a perspectiva de Richards, simboliza os vínculos entre as pessoas. Recusar ou restringir o consumo do prato compartilhado, comer só e/ou de forma diferente, são práticas diretamente contrárias ao comportamento consoante ao ritual que a comensalidade enseja.

Nessa perspectiva se constitui um campo complexo de sentidos de que se revestem os comportamentos ambíguos $e$ cercados de sentimentos incômodos: recusar ou ceder à tentação de uma caipirinha, ou de um docinho; improvisar uma refeição "saudável" com espacialidade e temporalidade próprias, ou tentar administrar limites "aceitáveis" de participação na comensalidade.

\section{Individualidade somática}

A prática associativa dos diabéticos, além de promover a troca de experiências acerca das dificuldades referidas anteriormente, também promove a aproximação com 
determinados valores da vida moderna. Esses valores são articulados através das atividades educativas nas quais os associados se familiarizam com os saberes das práticas do cuidado de si.

Os grupos de psicoterapia da associação também compõem o conjunto de estratégias para fazer com que o diabético aprenda a lidar com a diabetes. Eles têm a proposta de se constituírem como espaços de expressão da dimensão mais pessoal e íntima dos associados. Suas práticas no conjunto das atividades da associação são justificadas por se ocuparem do "emocional", que é tido como um dos fatores que afetam a condição de saúde do diabético.

A perspectiva que legitima a atuação dos profissionais na associação baseia-se em determinadas representações acerca da conjugação entre manifestações emocionais e fisiológicas. Essas representações são propostas aos associados através de formas de cuidar de si, que orientam a atenção para um conjunto de problemas e questões que, ainda que de natureza não orgânica, corporal ou física, mas psicológica, emocional ou mental, devem compor o leque de preocupações do cuidado com a diabetes.

O processo educativo sobre a diabetes no contexto popular se encontra diante da relação, apontada por Luiz Fernando Duarte (2003:177),

entre as representações individualizadas ou
individualizantes dos agentes da biomedicina e as
representações holistas dos pacientes dos ambulatórios,
clínicas, hospitais e demais serviços de saúde públicos. ${ }^{12}$

O conjunto de representações que orientam o diabético para o cuidado de si pode ser compreendido como estando em ressonância ou sendo parte do modelo de individualidade

${ }^{12}$ Para Duarte $(2003: 177)$ a pesquisa em contextos populares permite a investigação do "potencial heurístico do indivíduo/pessoa para a compreensão dos fenômenos da saúde/doença". 
O gênero do cuidado de si

somática referido por Carlos Novas e Nikolas Rose (2000). Na reflexão que esses autores fazem acerca das novas "estratégias de vida" dos sujeitos sob o impacto da nova genética molecular, ocorre uma ampla transformação na constituição da condição de pessoa, na qual, relações novas e diretas são estabelecidas entre o corpo e o self. Novas e Rose referem-se ao fato de que os leigos passam a dominar a linguagem da descrição e do julgamento da biomedicina (id.ib.:487-8). O cuidado de si emergiria como uma disposição central no quadro da individualidade somática. Entretanto, essa disposição produz uma série de tensões nas experiências e representações que os diabéticos têm acerca das relações sociais. No discurso educativo da associação, as representações sobre as práticas do cuidado de si se chocam com formas de concepção do eu tecidas fundamentalmente pelas relações de obrigação e apoio familiar.

Selecionei alguns temas que a psicóloga de um dos grupos desenvolve na interação com os associados, ao longo das discussões sobre os relatos que eles compartilham com os demais membros nas sessões do grupo. A ideia é de explorar algumas das propostas com as quais são orientados a produzir mudanças em seu modo de ser - a fim de lidarem melhor com os problemas dos quais se queixam. Com isso é possível ampliar a compreensão acerca do modo como as práticas dos diabéticos são forjadas pela disposição para o cuidado de si.

"Aprender a ser só junto com os outros". Essa foi a ideia com que me deparei no esforço de encontrar um sentido para a ética que caracteriza a condição do bom diabético. Alguns excertos das discussões do grupo me levaram a ela: "Ninguém pede para alguém morrer junto"; "Você nasce só e morre só"; "Ninguém cuida de ninguém, somente a própria pessoa decide se cuidar". Essas colocações fizeram parte de uma discussão sobre a solidão. A psicóloga apontara duas situações básicas que dependiam unicamente da própria pessoa: "cuidar-se e tomar decisões". Em uma passagem muito significativa dessas discussões, anotei em meu caderno de campo: 
A cada pessoa cabe perguntar-se "O que é importante para mim?". A essa colocação seguiu-se a sugestão de que esta atitude deveria se dar mesmo diante do cuidado com os filhos. O comentário advertia sobre a dedicação excessiva aos filhos. Quer dizer, mesmo se tratando dos próprios filhos, ainda se manteria a necessidade de buscar realizar aquilo que é importante para si; procurando, então, a melhor forma de equacionar as duas coisas (...) A conclusão que se encaminhava era a de que preservar a individualidade não ameaçava ou seria contrária à dedicação à família (Caderno de campo).

A perspectiva proposta infla de tal forma a dimensão do eu, que a torna de certa forma incompatível com as disposições relativas à experiência das relações familiares tais como foram vividas no passado. A mãe cuidadora deve ceder lugar para o sujeito centrado em si, ocupado consigo. A predisposição do sujeito que assume a responsabilidade do cuidado de si provavelmente soa por demais egoísta para quem diz que "os filhos valem qualquer sacrifício". Esse eu parece vir à tona para que seja constatado o quanto se errou na forma de se conduzir no passado, ao "deixar-se de lado" para ir ao suporte das necessidades do outro; enfim, quão errado foi o que parecia o mais certo e valorizado a fazer: "Eu era submissa, eu era supermãe, super-mulher", como expressou-se Selma no grupo Corpo $e$ Mente (Caderno de campo). Um eu que dá um tom agudo ao deslocamento de referenciais que se apresenta como solução para a experiência da solidão, ao propor uma experiência individual mais autônoma do sujeito que se ocupa mais com o cuidado de si mesmo.

Dessa transformação faz parte uma atitude crítica com relação aos valores transmitidos socialmente. A capacidade de fazer suas próprias escolhas é central. É preciso que a pessoa conheça a si mesmo, descubra seus gostos, descubra o que lhe dá 
O gênero do cuidado de si

prazer. ${ }^{13}$ Por exemplo, uma das formas como a psicóloga procura orientar sobre as transformações que as pessoas precisam empreender em suas vidas, de modo a viverem melhor, é a de se referir à necessidade de "tornar as coisas conscientes, enxergálas". Dessa forma, o sujeito ganharia condições de fazer frente à "força do coletivo que impõe os valores através do inconsciente" (caderno de campo).

Os relatos feitos no grupo apontam para as transformações que os membros sentem no contexto das relações familiares e da vida ativa no mercado de trabalho, refletindo os conflitos acerca das formas de manutenção das redes de suporte material e afetivo $e$ de reciprocidade entre as gerações. A orientação para o cuidado com a diabetes implica a necessidade de "reelaboração" das formas de sociabilidade relacionadas ao desempenho dos papéis sociais relativos a essas instituições. E para isso os associados são convidados a "tomar consciência" de que precisam "enxergar" melhor as coisas, a fim de reorientar sua conduta nas relações.

A ênfase na responsabilização do indivíduo sobre as condições de sua vida, a partir da constatação sugerida de que "ninguém cuida de ninguém", ou de que "ser só é uma condição do homem", dialoga, em sentido inverso, com os pressupostos das relações familiares do cuidado e do apoio mútuo. Para cuidar da diabetes o diabético precisa voltar-se para si e reorientar a relação que mantém com os outros. O que significa, por exemplo, que a mulher idosa deve assumir plenamente a prática do cuidado de si, ajustando-a ao envolvimento com as práticas sociais familiares. $\mathrm{O}$ cuidado de si passa a ter precedência. $\mathrm{O}$ cuidado com o outro não deve ameaçar o bem estar de quem cuida.

Duas perspectivas se apresentam em conflito na fase de vida atual dos membros do grupo pesquisado: por um lado, o

${ }^{13}$ É significativa a forma como, contando sobre um momento da vida em que passou por uma depressão, uma das interlocutoras de Assunção (2008:8) se expressou: "Antes [da depressão] eu não sabia nem quem eu era. Sabia que um filho não gostava de ervilha, que o outro não gostava de abóbora. Não sabia do que eu gostava". 
horizonte de uma vida caracterizada pela individualidade e pelo cuidado de si; por outro, a manutenção de uma postura voltada para o apoio do outro.

Como reconhecem os autores que se preocupam com os processos através dos quais responsabilidades antes tomadas como questões coletivas são cada vez mais atribuídas aos indivíduos ${ }^{14}$; o princípio individualizador do discurso biomédico exige que cada um seja parceiro ativo e responsável pela própria saúde. Rose (2001:20-1) aponta o fato de que, no mundo contemporâneo, os seres humanos estariam cada vez mais próximos de compreenderem-se em termos somáticos, fazendo com que a corporalidade se torne um dos mais importantes lugares para a auto-identificação e para aplicação de técnicas $e$ julgamentos éticos. A individualidade somática torna-se aberta à escolha, à prudência e à responsabilidade.

Se, por um lado, a tendência ao aumento da individualização na vida moderna é representada positivamente como sendo a conquista da autonomia e da liberdade de escolha; por outro, atingir esse estado implicaria reverter uma disposição emocional e corporal para o cuidado do outro - um quadro complexo de valores e sensibilidades vividos por um longo tempo durante o período em que os filhos são dependentes de cuidados. Certamente, uma lição de casa muito difícil de aprender se tomarmos a experiência de solidão vivida por pessoas que durante grande parte de suas vidas mobilizaram seus corpos, a si mesmos e o modo de se conduzir na vida social, com valores que os guiavam para o outro, para o cuidado do outro, para a assistência $e$ apoio dos familiares, especialmente dos filhos.

Em seu estudo sobre a moralidade dos pobres em um bairro de São Paulo, Cynthia Sarti (2005:22) salienta que "A família, pensada como uma ordem moral, constitui o espelho que reflete a imagem com a qual [os pobres] ordenam e dão sentido ao mundo social". Para a autora, a família é fundamentada por um princípio

${ }^{14}$ Cf. Debert, 2004; Featherstone, 1991, Lash, 1997. 
O gênero do cuidado de si

de obrigação moral com o qual seus membros se definem como comprometidos entre si: "... são da família aqueles com quem se pode contar, isto quer dizer, aqueles que retribuem ao que se dá, aqueles, portanto, para com quem se tem obrigações" (id.ib.:85, destacado no original).

A autora destaca o caráter difuso da obrigação moral familiar, pois a reciprocidade não se pauta pelo interesse explícito ou pela troca imediata, mas pela confiança (id.ib.:86). Nesse contexto "... os pais que criam e cuidam são merecedores de profunda retribuição, sendo um sinal de ingratidão o não reconhecimento desta contrapartida" (id.ib.:82, destacado no original).

O padrão moral desenhado por Sarti faz parte do percurso familiar vivido pelo grupo pesquisado, e por isso é que, diante dos novos contextos de sociabilidade definidos pela condição de diabéticos, eles são instados a relativizar as formas de ser que os predispuseram ao compromisso com as obrigações morais da família enquanto projeto coletivo. Os profissionais que orientam sobre os cuidados com a diabetes evocam um padrão diferente de envolvimento nas relações sociais, o qual implica a preeminência do cuidado de si. Os hábitos alimentares, os horários dos medicamentos e do monitoramento da glicemia, a prática de atividade física, instauram nas situações sociais referidas a ênfase no eu, em lugar da ênfase no outro.

Uma questão crucial que desafia o grupo de diabéticos estudado é a de priorizar o cuidado de si a despeito do fato de que nas práticas sociais que sustentam sua experiência de vida, o cuidado é algo que se dá ou que se recebe. Dessa forma, voltar o cuidado para si mesmo significa a quebra no padrão de troca, $e$ um ataque ao princípio de obrigação moral que a família representa. Estaria sendo apontada a perspectiva da quebra das relações.

A análise que Marilyn Strathern apresenta em O gênero da dádiva (2006) oferece um aparato conceitual muito interessante para enriquecer a compreensão acerca desta quebra de relações 
que o cuidado de si sugere. A autora distingue dois modos de troca nas culturas melanésias: o modo mediado $e$ o não mediado. Enquanto o primeiro modo produz objetos "que podem circular entre pessoas e mediar a relação entre elas" ${ }^{15}$, no segundo modo, o não mediado,

\begin{abstract}
uma pessoa afeta diretamente a disposição de outra em relação a si própria, ou afeta a saúde e o crescimento dessa pessoa. Exemplos disso são o trabalho que os cônjuges fazem um para o outro ou a capacidade da mãe para fazer crescer uma criança dentro de si (...) Apesar da ausência de objetos mediadores, as interações desse último tipo têm a forma de uma troca, na medida em que cada pessoa é afetada pela outra... (id.ib.:271).
\end{abstract}

Segundo o raciocínio de Strathern, a relação não mediada, como uma troca, funciona através do caráter direto do efeito que os parceiros têm um em relação ao outro, criando uma dependência mútua entre eles (id.ib.:309). Percebe-se, então, que o cuidado do outro, tal como se mostra na comensalidade familiar, é uma disposição fundante das relações domésticas. A prática do cuidado diferencia a esposa do marido, define-os enquanto parceiros identificados enquanto tal por uma relação de dependência, de sexo cruzado $^{16}$, e não mediada.

A prática do cuidado do outro é uma forma de corporificação das relações sociais domésticas que investe a identidade feminina com os atributos de esposa, dona de- casa e mãe. Assim, voltar os cuidados para si mesmo na situação de comensalidade, como discutido anteriormente, ameaça a disposição para o cuidado do outro; a pessoa constitui a si mesma como objeto do tipo de cuidado ou atenção que dirigia ao outro.

\footnotetext{
${ }^{15}$ Sendo que a influência de uma pessoa sobre outra é levada consigo na "parte que circula entre elas". Cf. Strathern, 2006:270.

${ }^{16}$ Segundo Strathern, a relação mediada se dá entre parceiros de mesmo sexo, que aparecem como múltimplos em sua composição: "Sendo múltipla, a pessoa é também divisível, uma entidade que pode dispor de partes na relação com outras" (Strathern, 2006:279).
} 
O gênero do cuidado de si

Semelhante atitude pode representar a quebra das referidas relações familiares, através da ameaça dos laços de dependência mútua, que definem as pessoas umas com relação às outras através de seus interesses diferenciados.

Contando, portanto, que a pesquisa com os diabéticos na verdade aponta para questões mais gerais com respeito a nossas práticas sociais, as reflexões aqui apresentadas sugerem uma pergunta importante que pode orientar outras abordagens sobre a questão: Até que ponto o cuidado de si, suscitado pela ênfase crescente da responsabilidade individual da manutenção da saúde do corpo $^{17}$, pode "transformar"18 a arte de comer tomada enquanto um conjunto de "atos críticos de relacionamento $e$ reprodução social" (DaMatta, 1986:62)? Dito de outro modo, que sujeito é esse que come segundo o estilo e o jeito de quem zela cuidadosamente pela própria saúde e bem-estar? Como se caracterizam as suas relações?

\section{Referências bibliográficas}

ARNAIZ, Mabel Gracia. Em direção a uma Nova Ordem Alimentar? In: CANESQUI, A. M. e GARCIA, R. W. D. (orgs.) Antropologia e Nutrição: um diálogo possível. Rio de Janeiro, Editora FIOCRUZ, 2005, pp.147-164.

AsSUNÇÃO, Viviane Kraieski. Comida de mãe: notas sobre alimentação e relações familiares. $26^{a} R B A$, Porto Seguro/BA, 01 a 04 de junho, 2008.

\footnotetext{
${ }^{17}$ De forma semelhante ao que acontece com respeito à busca da beleza, na qual se incluem as preocupações estéticas relacionadas à moldura do corpo, elegância, rejuvenescimento, ou sensualidade, que também incluem um campo de cuidados com dieta e com a prática de exercícios físicos, por exemplo.

${ }^{18}$ Como coloca DaMatta "entre nós, como em muitas outras sociedades, a sexualidade e a arte de comer (sobretudo a comensalidade que deve acompanhar a ação de ingerir o alimento) ainda não se transformaram em assuntos inteiramente individuais" (DaMatta, 1986:62).
} 
CANESQUI, Ana Maria. Mudanças e permanências da prática alimentar cotidiana de famílias de trabalhadores. In: CANESQUI, A. M. e GARCIA, R. W. D. (orgs.) Antropologia e Nutrição: um diálogo possível. Rio de Janeiro, Editora FIOCRUZ, 2005, pp.167-210.

DAMATTA, Roberto. O que faz o brasil, Brasil? Rio de Janeiro, Rocco, 1986.

DEBERT, Guita Grin. A reinvenção da velhice: socialização e processos de reprivatização do envelhecimento. São Paulo, EDUSP/FAPESP, 2004.

DUARTE, Luiz Fernando Dias. Indivíduo e pessoa na experiência da saúde e da doença. Ciência \& Saúde Coletiva, vol. 8, no 1 , Rio de Janeiro, Associação Brasileira de Pós-Graduação em Saúde Coletiva, 2003, pp.173-183.

FEATHERSTONE, Mike. The body in consumer culture. In: FEATHERSTONE, Mike; HePWORTH, Mike; TURNER, Bryan S. (eds.) The body: social process and cultural theory. Londres, Sage, 1991, pp.170-96.

GARCIA, Rosa Wanda Diez. A antropologia aplicada às diferentes áreas da nutrição. In: CANESQUI, A. M. e GARCIA, R. W. D. (orgs.) Antropologia e Nutrição: um diálogo possível. Rio de Janeiro, Editora FIOCRUZ, 2005, pp.275-286.

LASH, Scott. A reflexividade e seus duplos: estrutura, estética, comunidade. In: BECK, Ulrich; GIDDENS, Anthony e LASH, Scott. Modernização reflexive: política, tradição e estética na ordem social moderna. São Paulo, Unesp, 1997, pp.136-206.

MACIEL, Maria Eunice. Churrasco à gaúcha. Horizontes Antropológicos, vol. 2, n 4, Porto Alegre-RS, UFRGS, 1996, pp.34-48.

MACIEL, Maria Eunice. Cultura e alimentação ou o que tem a ver os macaquinhos de Koshima com Brillat-Savarin? Horizontes Antropológicos, vol. 7, $\mathrm{n}^{\circ}$ 16, Porto Alegre-RS, UFRGS, 2001, pp.145-156.

NOVAS, Carlos e ROSE, Nikolas. Genetic risk and the birth of the somatic individual. Economy and Society, vol. 29, n 4, Londres, Routledge, 2000, pp.485-513. 
O gênero do cuidado de si

PITTMAN, Patricia. Género y calidad de atención. El caso de hipertensión $y$ diabetes en Avellaneda, Provincia de Buenos Aires, Argentina. Washington, Organização Panamericana da Saúde, OMS, 1999.

RICHARDS, Audrey I. Hunger and Work in a Savage Tribe: a functional study of nutrition among the southern Bantu. Londres, George Routledge \& Sons, 2004.

ROSE, Nikolas. The politics of life itself. Theory, Culture \& Society, vol. 18, n 6, Londres, Thousand Oaks e Nova Déli, Sage, 2001, pp.1-30.

SANT'ANNA, Denise Bernuzzi de. Bom para os olhos, bom para o estômago: o espetáculo contemporâneo da alimentação. ProPosições, vol. 14, $\mathrm{n}^{\circ}$ 2, Campinas-SP, Faculdade de Educação Unicamp, 2003, pp.41-52.

SARTI, Cynthia Andersen. A família como espelho: um estudo sobre a moral dos pobres. São Paulo, Cortez, 2005.

STRATHERN, Marilyn. O gênero da dádiva: problemas com as mulheres $e$ problemas com a sociedade na Melanésia. Campinas, Editora da Unicamp, 2006.

WITT, Regina Rigatto. Gênero e diabetes: implicações para o autocuidado. In: LOPES, M.J.M.; MEYER, D.E.; WALDOW, V.R. (orgs.) Gênero \& Saúde. Porto Alegre, Artes Médicas, 1996, pp.150-56. 